\title{
The house musk shrew Suncus murinus \\ as a new laboratory animal for \\ use in behavioural studies
}

\author{
Keitchiro Tsuji, Kiyoshi Ishi, Takashi Matsuo ${ }^{1}$, and Kazuaki Kawano ${ }^{2}$ \\ Department of Psychology, Nagoya University, Chikusa-ku, Nagoya 464-8601
}

\begin{abstract}
The house musk shrew Suncus murinus has successfully been domesticated for laboratory use both in the United States and Japan. Animals of this species have been found to be useful for behavioural studies in comparative psychology and the related fields. This article dealt with basic characteristics, ecological modes, maintenance of laboratory shrews, basic patterns of behaviour, and assessment of the species as a laboratory animal for behavioural studies. Basic characteristics covered phylogenetic status, morphology, growth, sensory functions, and motor functions. Although its ecology has not yet $b$ en systematically investigated due to the difficulties for observing animals in the wild, some findings on the seasonal and locational variations of the population density in its natural habitat were obtained on the basis of the result of trapping. Keeping and breeding the already domesticated animals in an artificial environment as well as domesticating wild-originating animals were described. Characteristics of the caravaning behaviour were mentioned in relation to its sensitive period, its formation patterns, and development of the sensory and motor functions. Those findings were discussed in connection with its adaptive significance. Also, characteristics of the reproductive behaviour were represented. Behavioural interaction between sexes is expected to determine mating outcome, since the female is an induced ovulator, having no ovarian, vaginal, or behavioural oestrus cycle. Sequential pattern of the behaviour was described with reference to the male's pacifying behaviours and the postejaculatory attack towards the partner female. Together with those two observations, the activity rhythm, aggressive and learning behaviours were mentioned. Lastly, this species was assessed as a laboratory animal for behavioural studies.
\end{abstract}

Key words : house musk shrew, laboratory animal, behavioural characteristics, ecological modes.

The house musk shrew Suncus murinus is the only species of insectivores that has successfully been domesticated for laboratory use both in the United States and Japan. We have so far been concerned mainly with observation of some behaviours of the domesticated house musk shrew.

In this article, we describe its morphology, physiology, ecological mode,

\footnotetext{
${ }^{1}$ The present affiliation: Department of Psychology, Aichi-Shukutoku Junior College

${ }^{2}$ The present affililation: Department of Psychology, Matsuyama Shinonome Women's College
}

and behavioural patterns. We also deal with keeping and breeding of the animals, and finally assess the species as a laboratory animal for behavioural studies.

\section{Basic Characteristics}

\section{Phylogenetic Status}

The house musk shrew is a species of genus Suncus, subfamily Crocidurinae, family Sor icidae, order Insectivora. It distributes in low -latitude areas ranging from eastern Africa to the south-western part of Japan, with its highest density in South Asia.

Insectivores, as the original mammalian order, appeared on earth at the Cretaceous 
period (143-65 million years ago) of the Mesozoic era, and since then has preserved its primitiveness while various animal species of different orders have been evolved from that order. Its neocortex is remarkably undeveloped. The encephalization quotient (EQ) obtained by $\mathrm{EQi}=\mathrm{Ei} / 0.12 \mathrm{Pi}^{2 / 3} \quad(\mathrm{Ei}$ : brain weight, $\mathrm{Pi}$ : body weight) for living insectivores ranges between 0.24 and 0.82 (mostly between 0.30 and 0.50 ), which is lower than the EQs of living rodents (Jerison, 1973).

\section{Morphological Characteristics}

The house musk shrew is the largest animal in the genus (Figure 1). Its head-to-tail length and body weight are $220 \mathrm{~mm}$ and $60 \mathrm{~g}$ for males, $200 \mathrm{~mm}$ and $40 \mathrm{~g}$ for females, as measured with domesticated animals originating from wild population in Japan. Genetical and geographical variations are quite remarkable with its size and coat colour.

A relatively straight spine, loose-fitting skin, and plantigrade ambulation mode make its trunk look flat. It has a small head and a long snout with tactile hair. The eyeballs are small, while the nose is rather big. A pair of musk glands (16 $\mathrm{mm}$ and $10 \mathrm{~mm}$ for long and short diameters) have their openings on both sides of the trunk, and the other musk glands are scattered over entire body surface. Sexual dimorphism is not distinct, because the male's genital organ is usually kept in the peritoneal cavity. Females are smaller than males, having thinner tails and three pairs of nipples at the inguinal region.

\section{Growth}

The doubling time (the time to reach a body weight double the weight at birth) is three days, the shortest among mammalian species. The pups, born immature, grows remarkably fast. Permanent teeth are all cut at the age of 14 days. Weaning usually occurs at 16-22 days, and behavioural independence is attained at 22-25 days, although the weaning is sometimes delayed with the animals raised in cages.

Both male and female come to sexual maturity at 30 days after birth. It, however, takes two or three weeks more for stable parturition. The female is a so-called in-

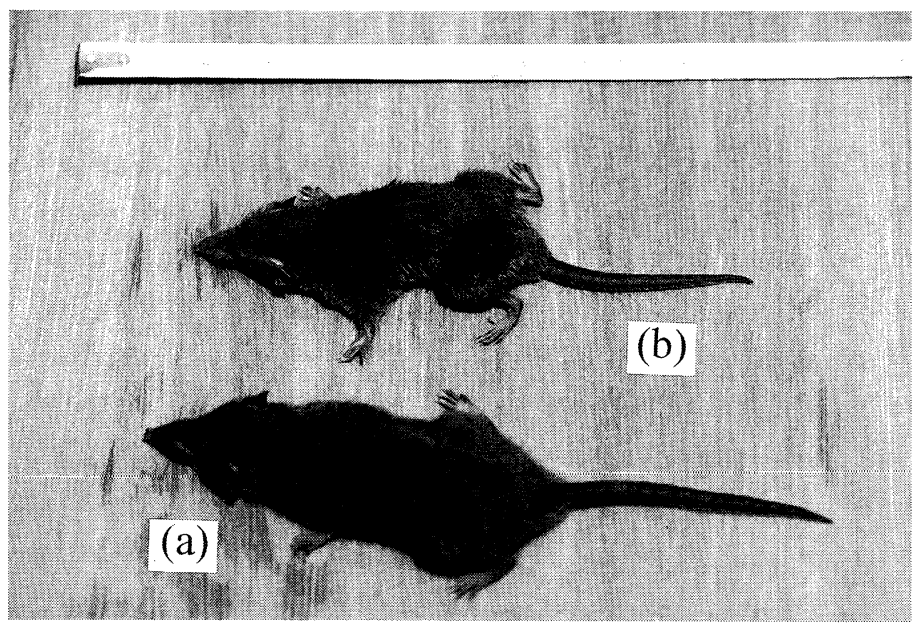

Figure 1. Adult male (a) and female (b) of the house musk shrew. 
duced ovulator, having no ovarian, vaginal, or behavioural oestrus cycle. The life span under artificial environment is estimated as around two years.

\section{Sensory Functions}

Eyelids open at the age of eight $( \pm 1)$ days, but the onset of visual function is delayed until the age of ten days due to the membrane covering the cornea. Both of rod and cone cells are observed by electron- microscopic inspection, while the density of the latter is low (Watanabe, Ohkouchi, and Toyama, 1980). The ability of light-dark discrimination and motion detection can be suggested by the fact that rhythms are entrained to lighting cycles and approaching occurs by moving objects.

Auditory function onsets at the age of six $( \pm 1)$ days, and seems to take important roles in orientation and behavioural interaction. Olfaction is sensitive, as is evidenced by anatomical and behavioural findings. However, sensory functions of this species have to be closely examined further by elaborated psychophysical measurements.

\section{Motor Functions}

The behaviour repertoire is basically similar to that of rats and mice. However, locomotor activity onsets and quickly develops before the onset of visual function, as is compared with rats and mice. Behaviours in a novel situation are not inhibitive, which shows that the neophobic tendency is weak. Caravaning occurs as an early behaviour (Tsuji and Ishikawa, 1984 ; Tsuji, Matsuo, and Ishikawa, 1986).

\section{Ecological Modes}

\section{Seasonal Variations of Population Density}

We made field-works in Tarama Island from 1980 to 1989 , for the purpose of ecological study of the wild animals. However, in spite of repeated attempts, it was almost impossible to examine their ecological modes by direct observation, since they have a quasiunderground activity-range and are basically nocturnal. We, therefore, chose the trapping method as an alternative one from which their ecology was inferred (Tsuji and Ishikawa, 1982). Table 1 gives the result of trapping.

Breeding has a seasonal variation with a low in April and a peak in June, while it is stable between July and November. The variation corresponds with meteorological conditions of the habitat. Seemingly, the between-year variation of breeding is caused by the environmental development of the village, as well as weather conditions at the time of trapping. The estimated density ratio of male to female is 1.6, ranging from 1.2 to 2.4 , which is approximately same as the value of 1.5 obtained with laboratory shrews.

\section{Locational Variation of Population Density}

Figure 2 gives the spatial distribution of wild animals by the number of animals captured as a function of the distance from the center of the village. It suggests that peak of the density is located at a wind-break 600 meters away. Seemingly, this finding differs from the previously reported result that the house musk shrew shares its living space with humans. The site of the highest density may have moved to the outskirts of village, being influenced by the renovation and reconstruc- 
Table 1. The result of trapping for wild shrews in Okinawa.

\begin{tabular}{|c|c|c|c|c|c|c|c|}
\hline No. & Mo. Yr. & Days & Traps & Captured & \%captz & M:F & ア $/$ 古 \\
\hline 1 & 6.1980 & 2.0 & 105 & 41 & 39.0 & $29: 12$ & 2.4 \\
\hline 2 & 10.1980 & 2.5 & 230 & 37 & 16.1 & $21: 16$ & 1.3 \\
\hline 3 & 4.1981 & 4.0 & 328 & 29 & 8.8 & $16: 13$ & 1.2 \\
\hline 4 & 3.1982 & 2.5 & 217 & 23 & 10.6 & $15: 8$ & 1.9 \\
\hline 5 & 6.1983 & 2.5 & 149 & 52 & 34.8 & $34: 18$ & 1.9 \\
\hline 6 & 11.1985 & 2.0 & 127 & 21 & 16.5 & $14: 7$ & 2.0 \\
\hline 7 & 7.1986 & 3.0 & 246 & 43 & 17.5 & $23: 20$ & 1.2 \\
\hline 8 & 6.1987 & 3.0 & 230 & 22 & 9.6 & $15: 7$ & 2.1 \\
\hline 9 & 6.1988 & 2.0 & 186 & 68 & 36.6 & $38: 30$ & 1.3 \\
\hline 10 & 6.1990 & 3.5 & 255 & 48 & 18.8 & $27: 21$ & 1.3 \\
\hline 11 & 2.1993 & 5.0 & 250 & 57 & 22.8 & $34: 23$ & 1.5 \\
\hline Total & - & 32.0 & 2323 & 441 & 19.0 & $266: 175$ & 1.5 \\
\hline
\end{tabular}

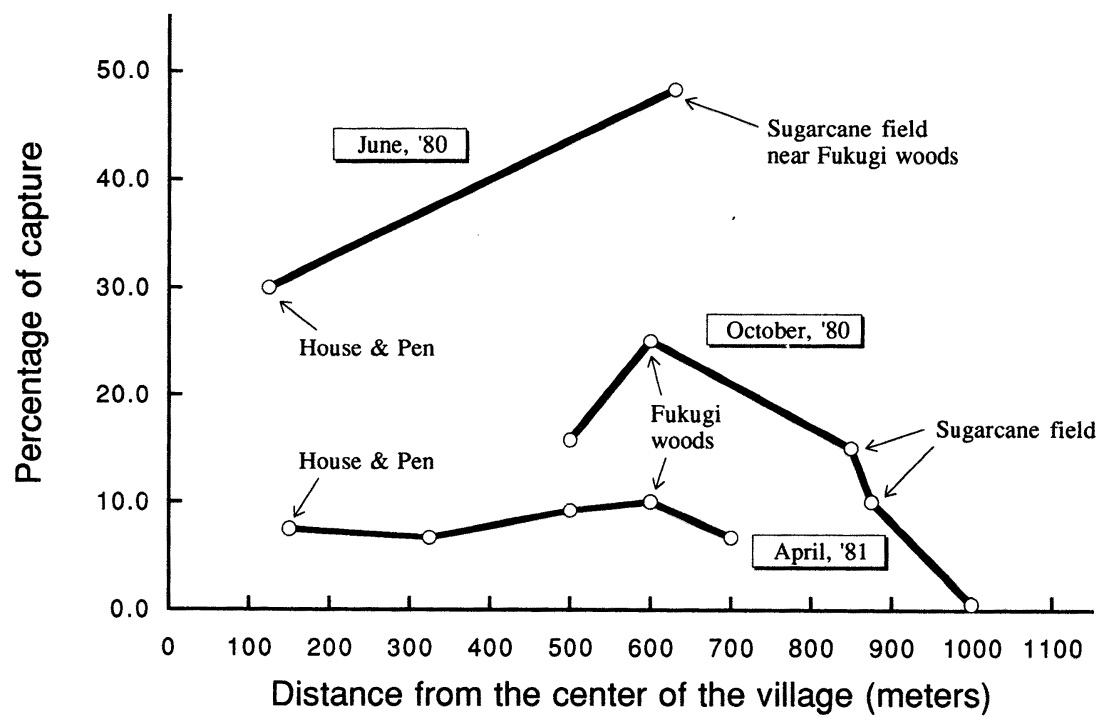

Figure 2. Percentage of capture as a function of the distance from the center of Tarama village (Tsuji \& Ishikawa, 1982).

tion in the residential area. It is probable that omnivorous animals are flexible in their adaptation to novel sites.

An observation of their traces (feces) has led us to conclude that their nest sites are in cool and airy places and that due to their high rate of basal metabolism they go out from their sites for foraging even in the daytime. 


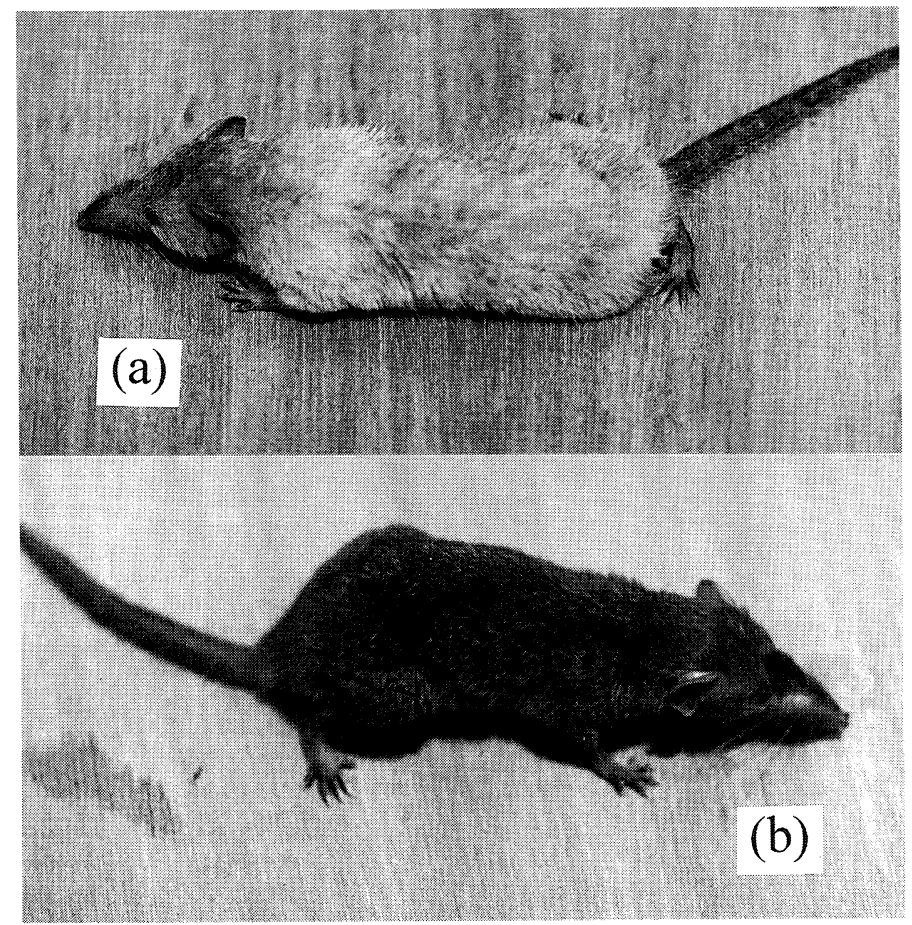

Figure 3. An example of variation in the coat colour in the early stage of domestication.

A white-coloured, non-albino shrew (a) appeared in the third generation, as compared with an agouti-coloured animal originating from wild population (b).

\section{Genetical Variation}

Additionally mentioned is that in 1980 an albino shrew was captured dead by trapping in Tarama. It was an adult male of average size and weight. Some of the animals originating from the wild showed a phenotype of white, not albino, coat colour (Figure $3 \mathrm{a}$ ) at the second and third generations of domestication.

Those facts suggest that there exists genetical variation even within a single wild population.

\section{Maintenance of Domesticated House Musk Shrews}

\section{Domestication of Wild Shrews}

The domesticated house musk shrew is the only laboratory animal in the order Insectivora. Domestication of wild shrews for laboratory use was independently undertaken both in the United States and Japan. In the United States, Dryden domesticated wild animals captured in Guam (Dryden, 1968, 1969). In Japan, Oda and Kondo successfully produced some lines of laboratory shrews which originated from wild animals captured in Nagasaki and Okinawa Prefectures (Oda and Kondo, 1977). The laboratory shrews are 
now available for research in various fields of biological sciences.

With special concern for the behavioural effects of domestication, we had made a similar attempt with wild shrews captured in Tarama Island, but did not succeed in obtaining animals exceeding four generations. Our attempt was restarted in 1993 with wild shrews captured in Ohzato Village, Okinawa, and domestication has been successfully continued to the 13th generation in 1999.

\section{Keeping Shrews}

Shrews are kept and bred in closed colony. They are individually housed in cages of acrylic resin $(220 \times 320 \times 130 \mathrm{~mm})$. In each cage, contained are a shelter for nesting, a food-tray, and a water-bottle. The floor is covered with shreds.

Animals can access ad libitum to food and water, which are regularly supplied once a week. Dried food for trouts (Nippon Haigoshiryo) mixed with that for cats by $2: 1$ has been found adequate for their growth. Shreds on the floor are renewed once or twice a week. Replacing the shreds too frequently may cause an undesirable effect.
In comparison with rats and mice, shrews are easily excited by artifacts. Since the female is highly aggressive, it must be carefully treated, particularly at mating and nursing periods. The use of long-sized tweezers is recommendable to make handling easy. Nest-box, whether for resting or breeding, helps shrews to adapt to their environment and make them stable, as is suggested from the fact that it remarkably reduces the level of aggression and prevents the possible occurrence of infanticide.

\section{Basic Patterns of Behaviour and Their Observation}

\section{Caravaning Behaviour}

Caravaning is widely known as an early behaviour which is observed in many species of Crocidurinae. As Figure 4 shows, the young shrews hold onto the fur of other shrews and thus the mother moves about with a line of pups trailing behind her.

The behaviour has been observed (Schacht, 1910 ; Wahlström, 1929, 1930 ; Niethammer, 1950 ; Zippelius, 1957, 1972 ; Ansell, 1964 ; Hanzak, 1966 ; Dryden, 1968 ; Vogel, 1970; Fons, 1972 ; Vlasak, 1972 ;

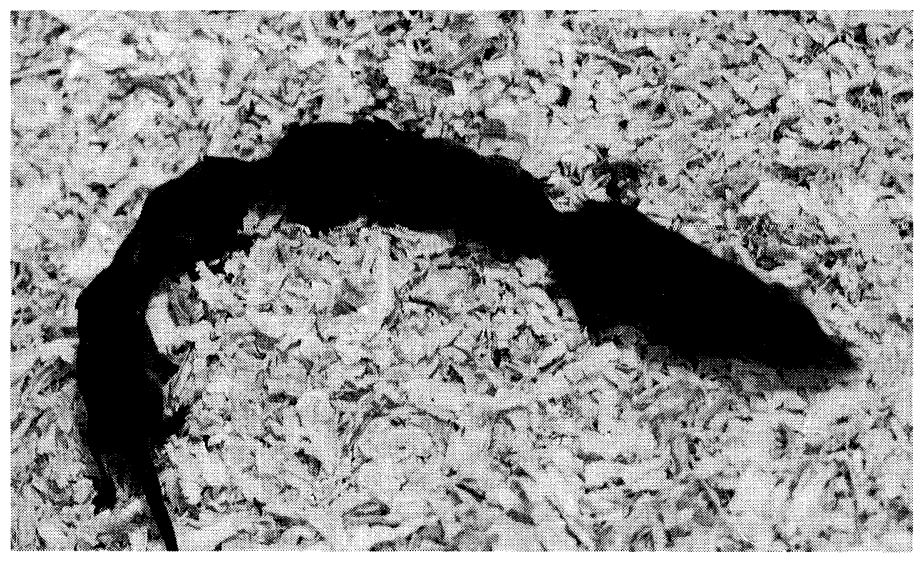

Figure 4. Caravaning behaviour in the laboratory open-field. 
Grünwald and Möhres, 1974; Dippenaar, 1979). However, the findings were rather limited because the observations were made with a small number of captured animals in uncontrolled conditions. As mentioned above, we have solved those problems by using laboratory shrews for observation and succeeded in making its basic characteristics clear (Tsuji and Ishikawa, 1984; Tsuji and Naruse, 1985 ; Tsuji et al., 1986).

Figure 5 gives the percentage of animals which showed caravaning as a function of pup's age in days. Caravaning occurred from five to 22 days of age, peaking at around 13 days. During the sensitive period, five different patterns of caravan appeared, as Figure 6 shows. Table 2 gives the description of each of the five patterns.

Figure 7 shows the frequency of each pattern of caravan formation as a function of the pup's age in days. Pattern IV which rarely appeared at the later stage of sensitive period is not shown here, because its fre- quency was low. Patterns I and II appeared at the earlier stage, while Pattern III increased after vision functioned, and was gradually replaced by Pattern $\mathrm{V}$ after the age of weaning. Those patterns were thus found to depend closely upon sensory and motor functions, and sequentially appeared in the course of development.

Maternal behaviour of this species is not marked as compared with that of many mammalian species. Mothers, showing basically nocturnal activity, leave their nest-sites every two to four hours. The high rate of basal metabolism seems to cause foraging with relatively brief intervals. Probably caravaning of this species has been built in as an efficient nursing strategy, in the process of evolution.

\section{Reproductive Behaviour}

Breeding can occur through the year. If oestrus is defined as receptivity to the male, female is in the state of continuous oestrus.

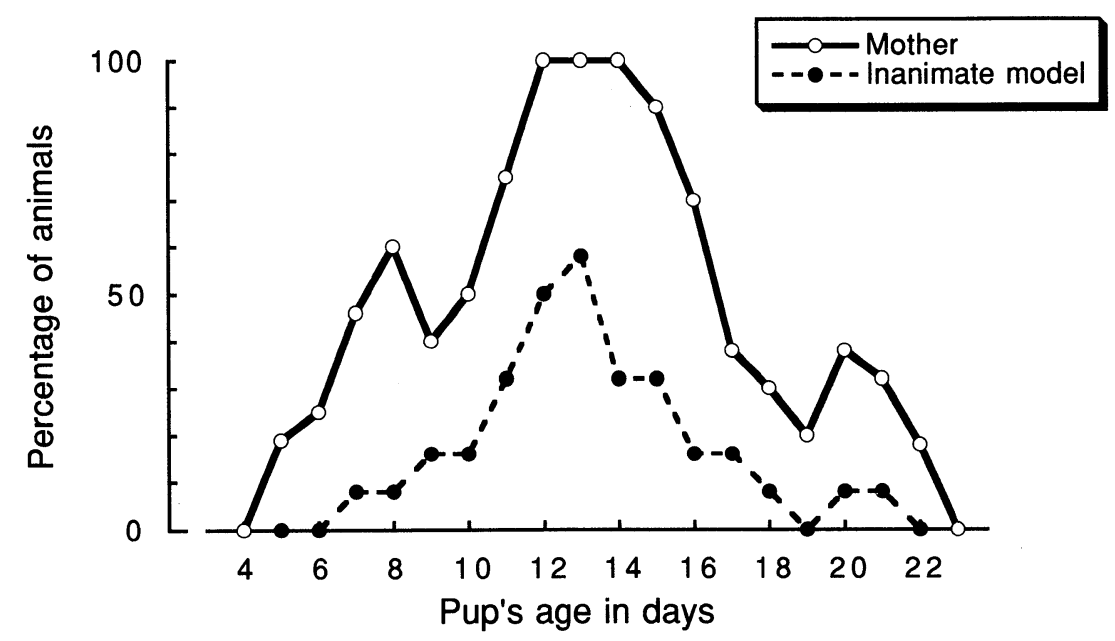

Figure 5. The percentage of animals which showed caravaning as a function of age in days (Tsuji \& ishikawa, 1984). The curve was obtained with 46 animals. 

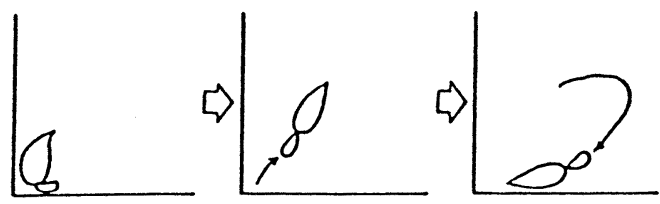

Pattern I
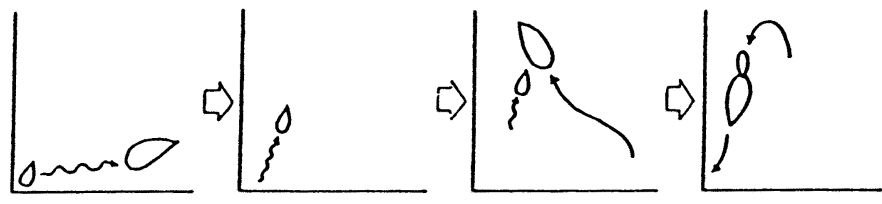

Pattern II
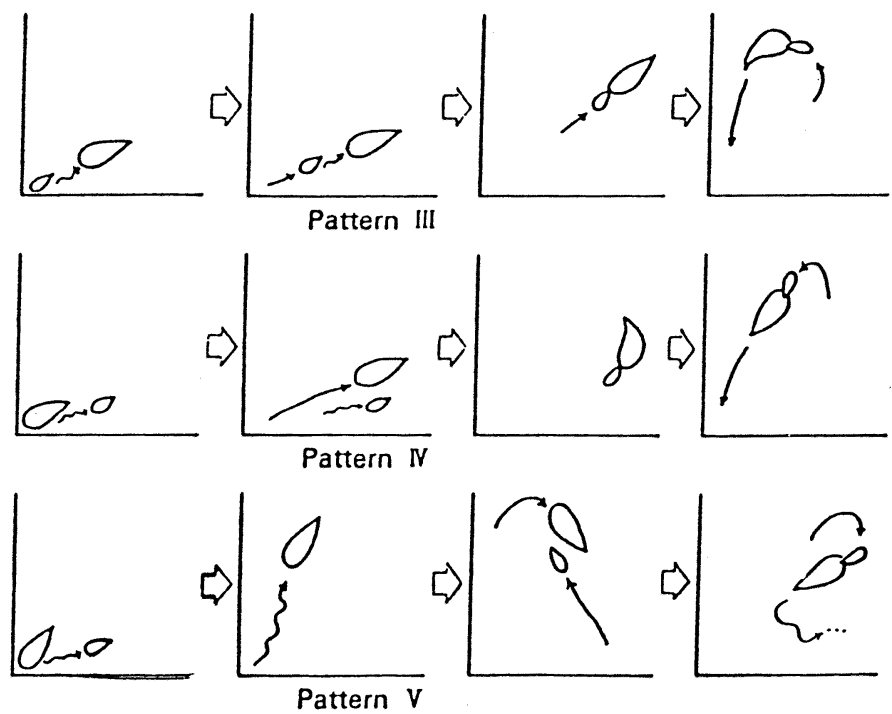

Figure 6. Five patterns of the caravan formation observed in the laboratory open-field (Tsuji \& Ishikawa, 1984).

Table 2. Characteristics of five patterns of the caravan formation.

\begin{tabular}{|c|l|}
\hline Pattern & \multicolumn{1}{c|}{ Behavioural characteristics } \\
\hline I & $\begin{array}{l}\text { A pup, while sucking and attaching the mother, forms caravan quickly when she leaves } \\
\text { the base. }\end{array}$ \\
\hline II & $\begin{array}{l}\text { After the mother slips out of the base, a pup moves blindly searching for her. When } \\
\text { the mother finds it, she quickly approaches from behind and makes contact with the } \\
\text { pup, which gives the opportunity to caravan. }\end{array}$ \\
\hline III & $\begin{array}{l}\text { When the mother leaves the base, a pup follows her uttering twitterlike sounds, catches } \\
\text { up with her, and holds onto her. }\end{array}$ \\
\hline IV & $\begin{array}{l}\text { A pup moves out while the mother stays still at at the base. The mother, noticing it, } \\
\text { makes a straight approach and urges the pup to caravan. }\end{array}$ \\
\hline V & $\begin{array}{l}\text { A pup, being independent of the mother and littermates, moves about explorig the field. } \\
\text { Then, the pup runs at the mother to form caravan, when frightened with an unexpected } \\
\text { stimulus. }\end{array}$ \\
\hline
\end{tabular}




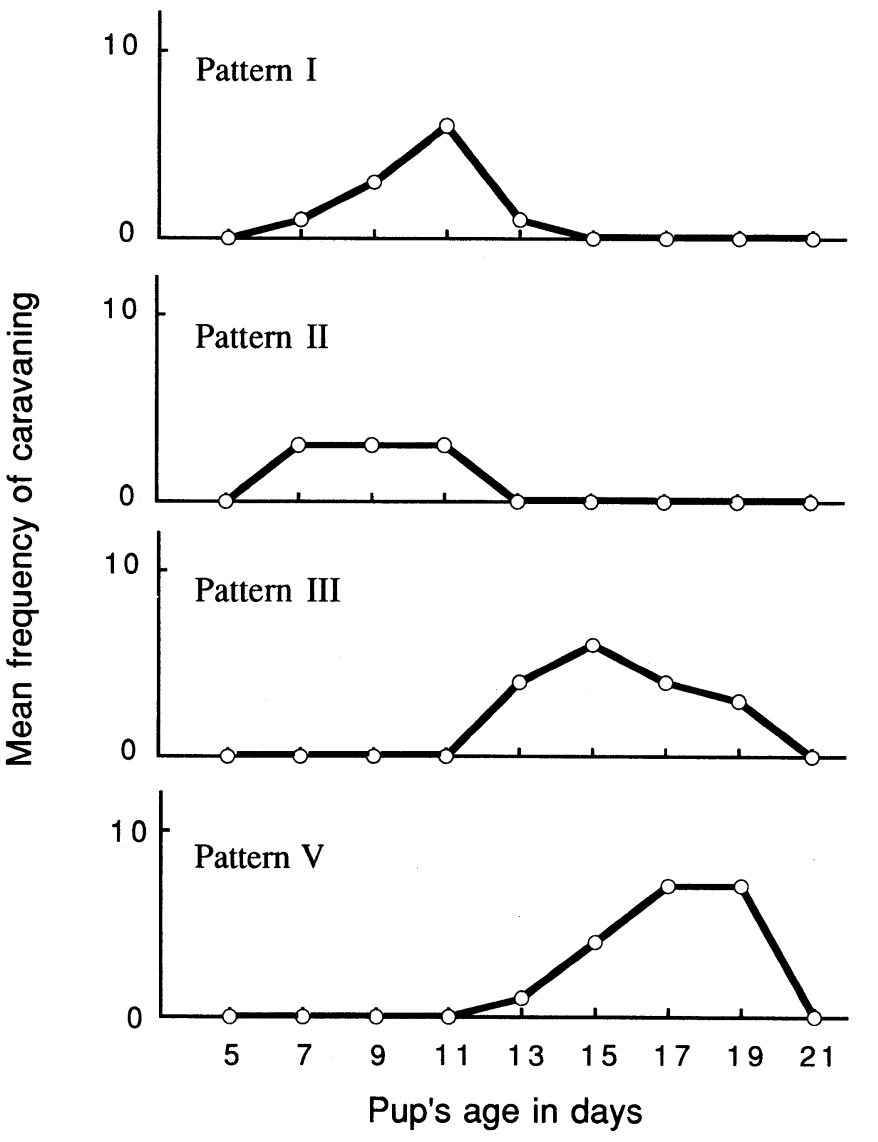

Figure 7. The frequency of caravan formation with pup's age for each of four patterns (Tsuji et al., 1986; Tsuji, 1988).

The female is an induced ovulator, and has no ovarian, vaginal, or behavioural oestrus cycle. The behavioural interaction between sexes is therefore expected to determine their mating outcome. Rissman and her colleagues reported the effect of endocrinological variables upon reproductive behaviour of this species (Rissman, 1987 ; Rissman and Bronson, 1987). Nevertheless, the behaviour had not been fully understood until we made a series of observations (Tsuji, 1987, 1988, 1989, 1991). Figure 8 gives the sequential pattern of behavioural interaction between sexes.

The female initially showed intense aggressiveness towards the partner male, a behaviour which induced the male to pacify the female. The pacifying behaviour included tail-wagging and vocalization (emission of a sound similar to the pup's isolation call). The female became receptive and came to permit the male to approach and contact. The male repeated the sequence of contact-following, mounting, and penis-intromission while pacifying the female, before finally succeeding in ejaculation.

Interestingly, the male showed a sudden change in behaviour after ejaculation. The male poked and bit the female while emitting a particular sounds to pacify the partner. 


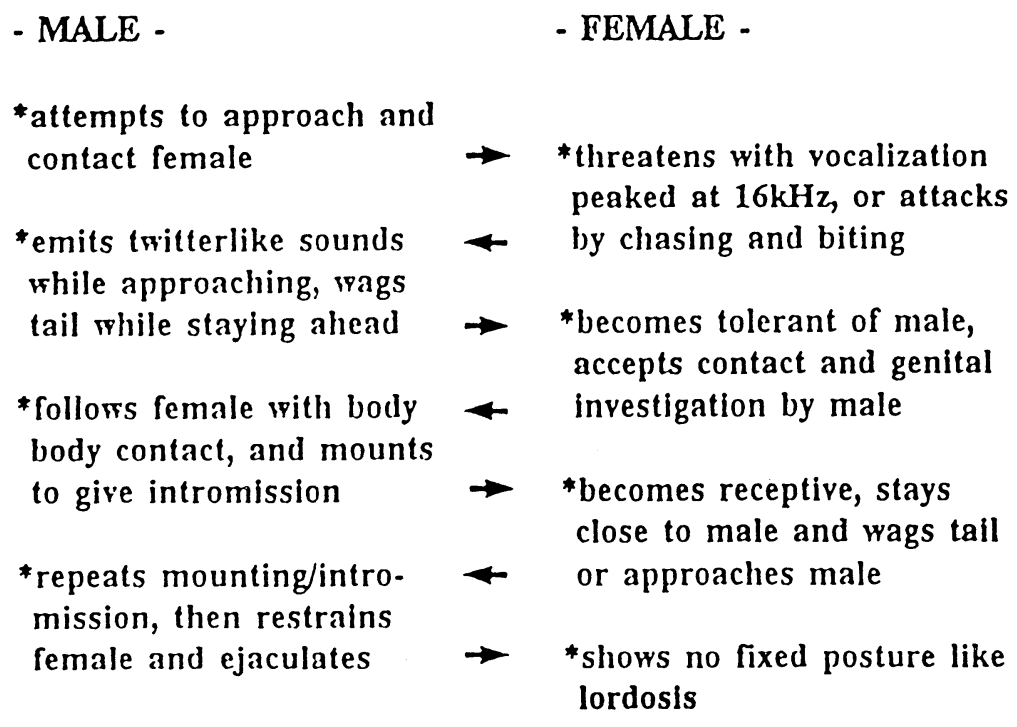

*turns aggressive, pulls or poking female while emitting twitterlike $\quad \rightarrow \quad$ *initially still receptive but sounds "Postejaculatory attack"

Figure 8. The sequential pattern of sexual behaviour (Tsuji, 1987, 1990).

Since this kind of attack was found to differ from intermale/interfemale agonistic behaviour in some respects, it was named "postejaculatory attack" by Tsuji (Tsuji, 1988). Its adaptive significance was also investigated (Tsuji, 1990, 1993).

\section{Activity Rhythm}

Few studies have been concerned with biological rhythms of this species (Balakrishnan., Nair, and Alexander, 1972 ; Balakrishnan and Alexander, 1979). Activity rhythms were obtained with domesticated shrews by recording their wheel-running in homecages over 15 days (Matsuo and Tsuji, 1987).

Figure 9 illustrates three types of act- grams obtained in the $12 \mathrm{~L} 12 \mathrm{D}$ cycles (L: 0800-2000, D : 2000-0800). Type A showed the nocturnal rhythms, in which wheel-running rarely occurred during the light period. The ratio of amount of activity in the light period to total amount in a day did not exceed $10 \%$. Type B showed the active phase both in the light and dark periods with relatively inactive phases appearing at transitory periods from dark to light and vice versa. Consequently the difference in the amount of activity between the light and dark periods was blurred. Type C lacked rhythmicity. Wheel- running appeared evenly throughout the day with no particular peaks. As Table 3 shows, Types A, B, and C occupied 42.8\%, 39. 


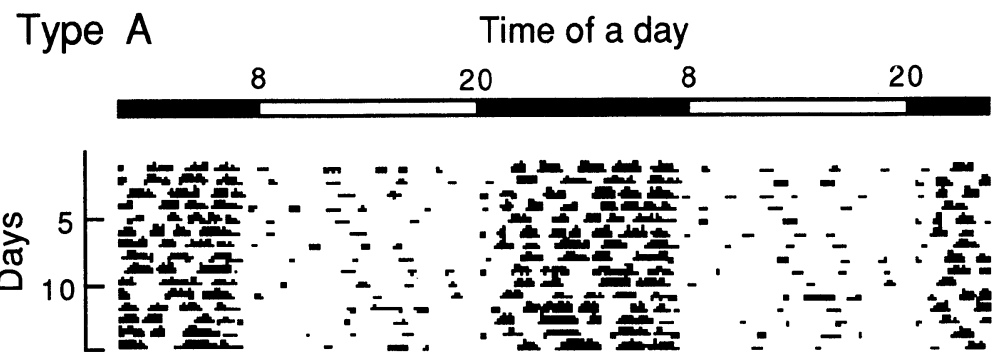

Type B

\begin{tabular}{rrrr}
6 & 18 & 6 & 18 \\
\hline
\end{tabular}

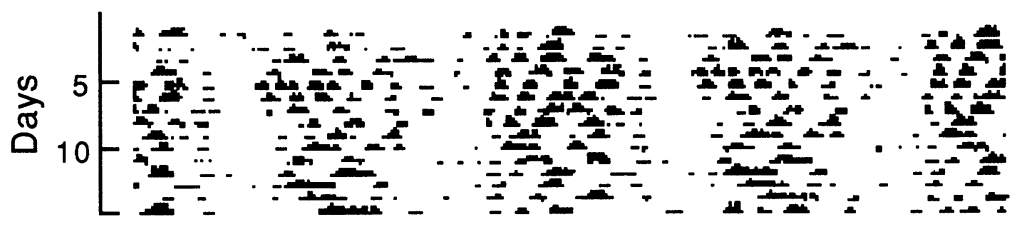

Type C

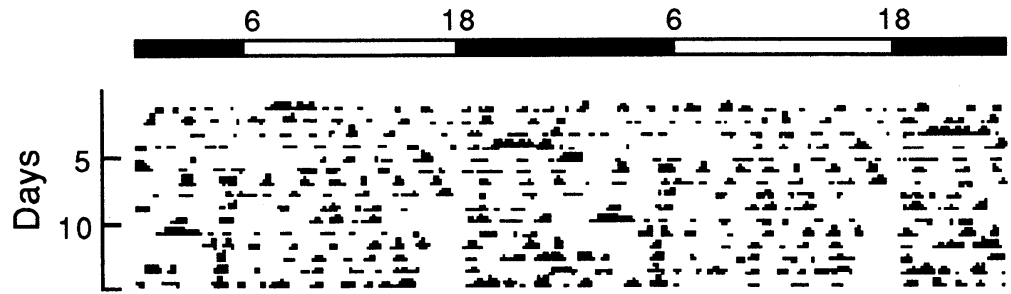

Figure 9. Actgrams showing three types of the wheel-running activity in 12L12D cycles (Matsuo \& Tsuji, 1987).

Table 3. The number of animals classified into each of three types of activity (Matsuo and Tsuji, 1987).

\begin{tabular}{|c|c|c|c|c|}
\hline Activity rhythm & Type A & Type B & Type C & Total \\
\hline Males & $9(50.0)$ & $6(33.3)$ & $3(16.7)$ & $18(100.0)$ \\
\hline Females & $3(30.0)$ & $5(50.0)$ & $2(20.0)$ & $10(100.0)$ \\
\hline Total & $12(42.8)$ & $11(39.3)$ & $5(17.9)$ & $28(100.0)$ \\
\hline
\end{tabular}

The number in parenthesis indicates the percentage.

$3 \%$, and $17.9 \%$, respectively, where no significant difference was found between males and females.
The rhythms of locomotor activity obtained by another investigators also showed three types, in spite of the difference 
in lines used (Aoki, Saito, Ebukuro, Hioki, and Takahashi, 1993). Type A (named Type $\mathrm{B}$ by the original authors) showed the nocturnal pattern, in which $70 \%$ of the daily amount of activity appeared in the dark period. Type B (originally named Type A), which was observed in only two of 13 animals, showed a greater amount $(60 \%)$ of activity in the light period. Type $\mathrm{C}$, occupied by $50 \%$ of animals, lacked rhythmicity. Additionally, the amount of activity in the light period relative to the dark period was significantly greater for females than for males.

Drinking activity was recorded (Aoki, Saito, Hioki, Ebukuro, and Takahashi, 1992). under the schedule of 12L12D (L: 0700-1900, D : 1900-0700). Similarly, there were three types of rhythms. Type A was nocturnal. Around $70 \%$ of activity occurred in the dark period. In Type $\mathrm{B}$ (named Type $\mathrm{C}$ by the original authors), drinking occurred from the second half of the light period to the first half of the dark period. Type C (named B by the original authors) lacked rhythmicity, where drinking was dispersed throughout the day. Among 13 animals examined, four (30.7\%) were classified as Type A, four (30.7\%) as Type B, and five (38.6\%) were as Type C.

While the remarkable variation in rhythms with a single line might have been partly due to a small number of domesticating generations, the indistinct rhythmicity could be attributed to the high rate of basal metabolism.

\section{Social Behaviour}

Territoriality was not demonstrated with this species in captivity (Kawano and Tsuji, 1991). We attempted to examine territoriality and nest-site preference in homecages, but the results were inconclusive.

Kawano made a series of experiments on intermale, interfemale, and male-female aggressions (Kawano, 1992). He analyzed each of those interactions by means of sequential patterns and item frequencies. Initially, either or both of the animals paired emitted threatening sounds, bit the other's body, or wrestled. Interaction thus began with aggressive behaviours. There was a distinct difference among intermale, interfemale, and male-female pairs, as Figure 10 shows.

Males showed more diverse responses to the partner of the same sex than the females did, although females were more aggressive than males. Intermale interactions consisted of frequent approach (facing) and escape, while interfemale interactions included alarm vocalization in addition to all the patterns found in intermale interactions. In malefemale interactions, some components of reproductive behaviour were observed. Males smaller in weight approached and escaped more frequently than the larger males, whereas the body weight had no effect on the behaviour of female-female pairs.

\section{Learning Behaviour}

As the first step of investigating the learning ability of this species, we examined whether laboratory shrews can form the learning set. The rate of its formation has been used as a measure to compare the learning ability among different species which differ in sensory ability and response repertoire. We examined the possibility of forming the learning set with the procedure of continuous reversal tasks (Ishii and Tsuji, 1987).

Animals were run in a $\mathrm{Y}$-shaped maze 
(a) Male-male pair

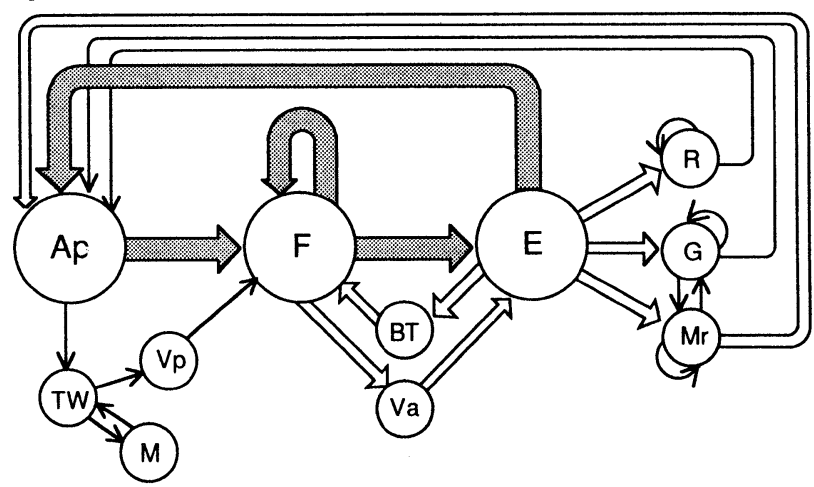

(b) Femal-female pair

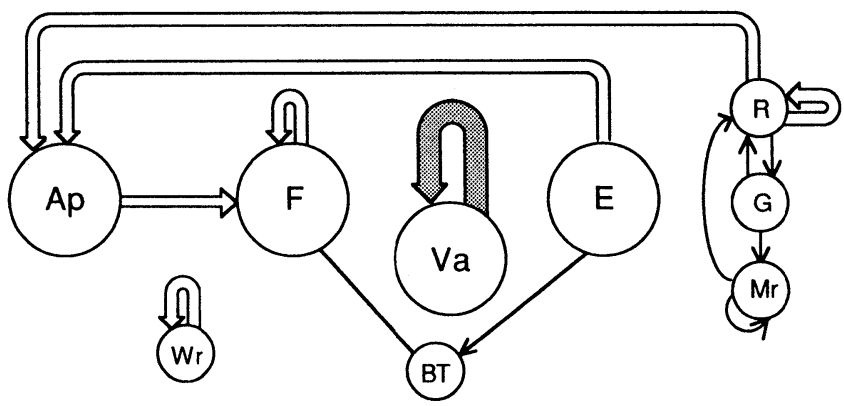

(c) Male-female pair
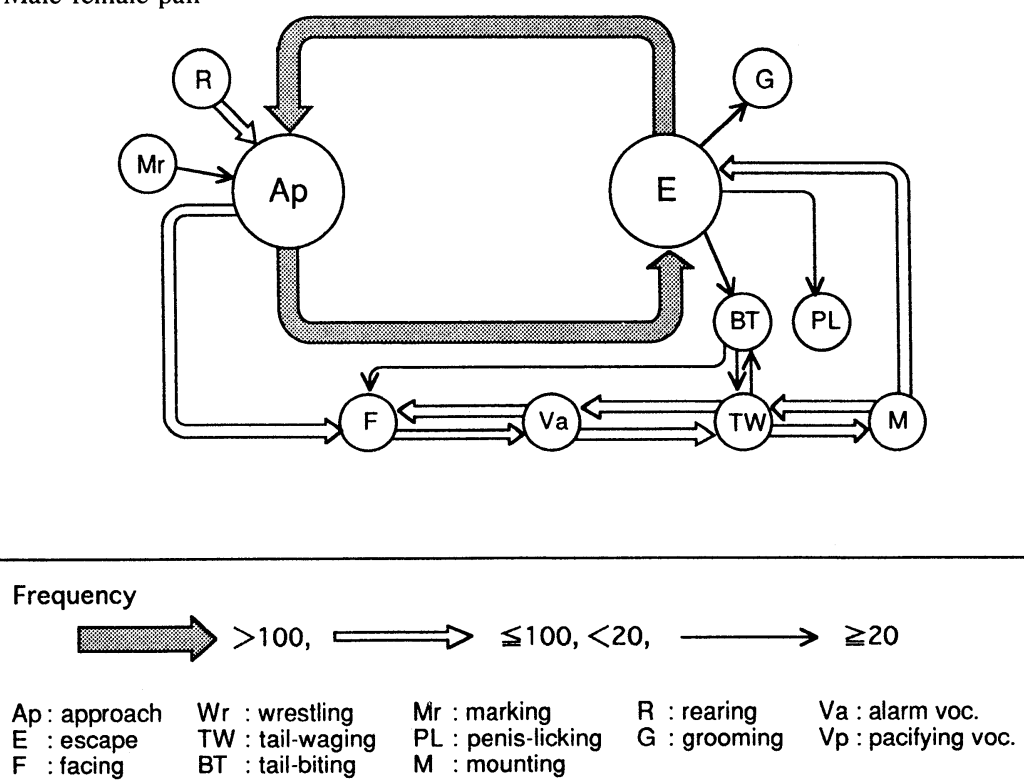

Figure 10. Inter-individual transition of behaviours in male-male pair (a), female-female pair (b), and male-female pair (c) (Kawano, 1992). 
for spatial discrimination with food-pellet rewards. Figure 11 gives the percentage of correct responses in the original training. Learning proceeded in a similar way as with rats, as is shown by the inset curve in the figure.

Figure 12 gives the percentage of correct responses in the process of reversals. Performance was improved with the number of reversals, which demonstrated formation of the learning set. Individual differences in the performance were rather remarkable. It might have been caused by heterogeneity in the laboratory shrews due to a relatively brief period of domestication.

Also, avoidance response was trained. Figure 13 gives the percentage of avoidance as a function of trials. Improvement occurred markedly in the second block of four trials (Ishii and Tsuji, 1988). As Figure 14 shows, latency to escaping was reduced in a negatively accelerated curve.
The two experiments mentioned above demonstrated that animals of this species can cope with their environment flexibly, in spite of a low level of encephalization. A weak tendency of neophobia might help them to increase the probability of being reinforced. It is one of our further tasks to elaborate systematically the ability and the level of learning so that evolutionary process can be depicted in its relation.

\section{Assessment of the House musk Shrew as a Laboratory Animal}

\section{Advantages}

Although only a small number of behavioural studies have so far been made with the house musk shrew, the following are mentioned as positively assessed for laboratory use.

As mentioned earlier in the section of phylogenetic status, this species is expected to provide us with an important information in the field of comparative studies of

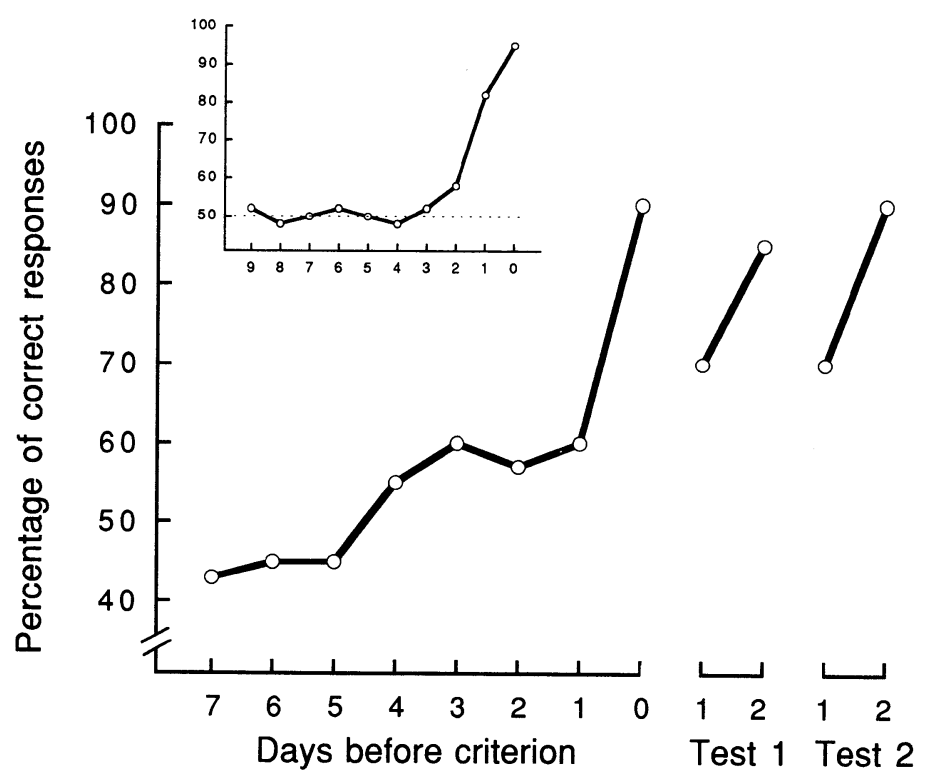

Figure 11. The percentage of correct responses with trials in the learning of the Y-shaped maze (Ishii \& Tsuji, 1987). 
TSUJI, et al. : The house musk shrew as a new laboratory animal

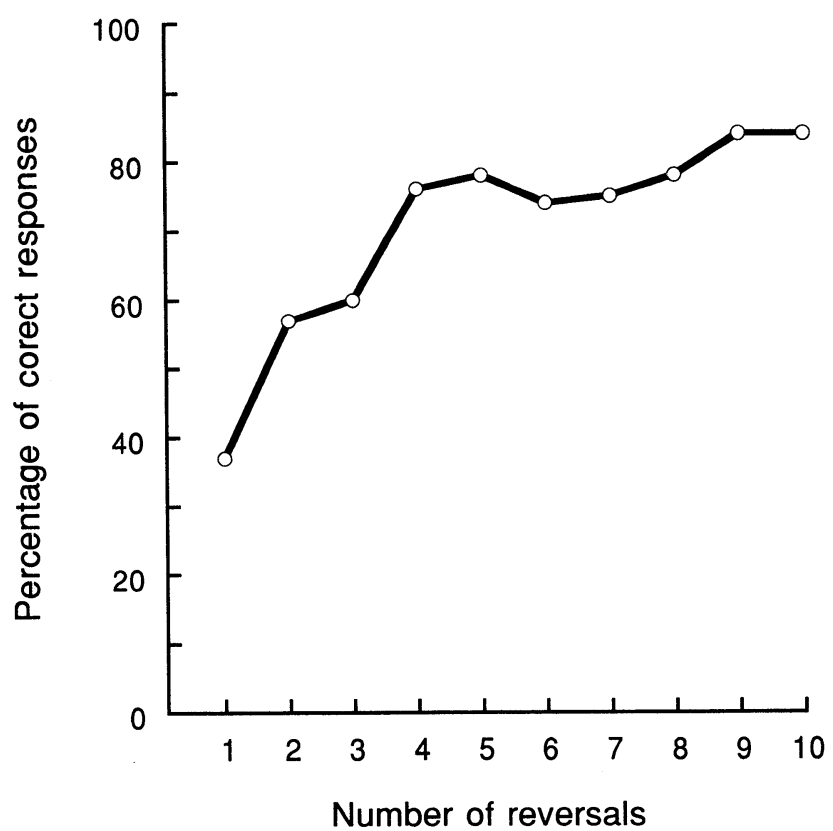

Figure 12. The percentage of correct responses as a function of reversals in the learning of the $\mathrm{Y}$-shaped maze (Ishii \& Tsuji, 1987).

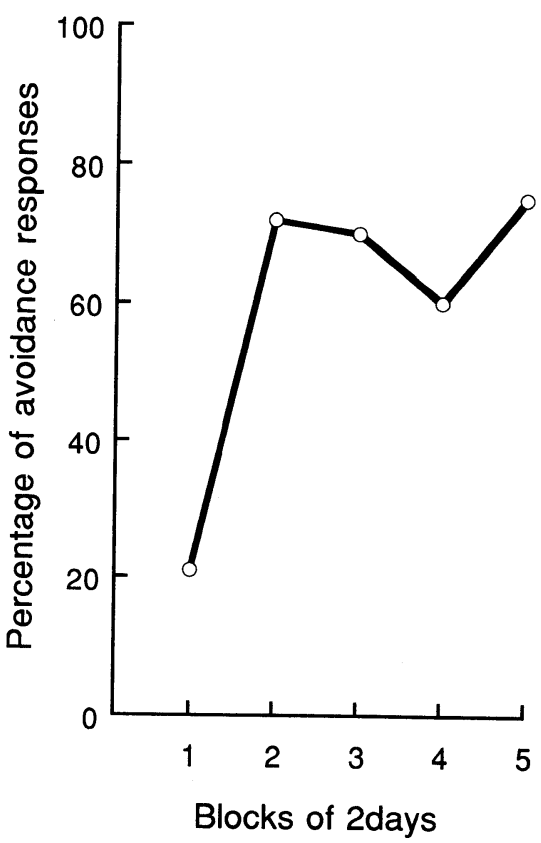

Figure 13. The percentage of avoidance responses with trials (Ishii \& Tsuji, 1988).

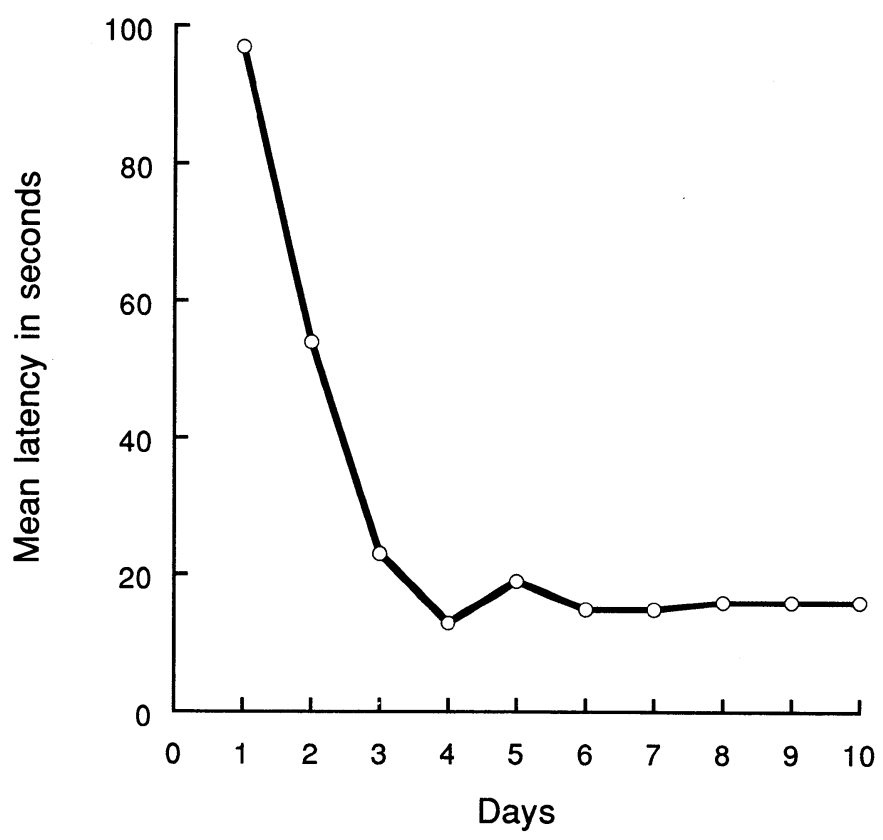

Figure 14. The latency to escaping as a function of trials (Ishii \& Tsuji, 1988). 
behaviour. Animals of this species seem to have preserved the nonspecific or undifferentiated modes of adaptation which are shared by a wide range of mammalian species. Therefore, observation of their behaviours possibly leads us to formulating a general law of behavioural adaptation.

Compared with animals of other orders, this species seems to be more versatile in the basic mode of behavioural coping with environment. Neophobia is weak, and even wild animals actively show the exploratory behaviour. Since their behaviours are not markedly inhibited and can be easily identified in laboratory environments, animals are easily placed in a test situation.

Undoubtedly, how those traits are assessed depends upon the purpose of individual researches. However, brief history of domestication could be a merit, when we attempt to follow up the behavioral effect of domestication by starting from originally wild animals.

\section{Disadvantages}

Figure 15 gives a histogram of litter-sizes for three lines of laboratory shrews. The litter-size is small, ranging from two to six with a mean value of 2.7. Infanticide often occurs at nursing period. It is thus laborious and time-consuming to get a stable breeding outcome. In addition, handling of animals is not easy because of their low level of docility. The insufficiency of the basic information on ecology also makes it difficult to set up an ecologically valid situation in the laboratory. Some of those disadvantages seem to come from brief history of domestication, some are species-specific, and others are attributable to scarcity of research findings on this species.

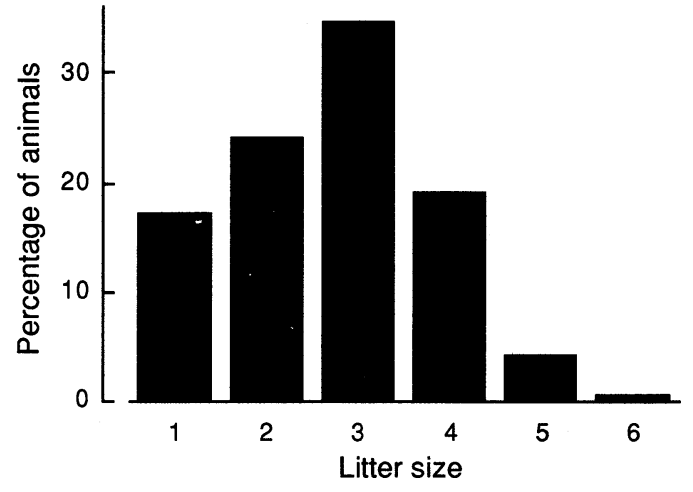

Figure 15. The number of litters in the domesticated animals.

\section{Acknowledgment}

This work was supported in part by a Grant -in-Aids for Scientific Researches from the Ministry of Education, Science and Culture of Japan, No. 60450012, 62450016, 04401004, and 09301005. We wish to thank Tomohiko Ishikawa, Hiroki Okuda, Keiko Niwa and Minoru Kojima, for their collaboration. Special thanks go to late Emeritus Professor Kyoji Kondo for inspiring this work.

\section{References}

Aoki, S., Saito, T. R., Hioki, K., Ebukuro, S., \& Takahashi, K. W. 1992 Diurnal rhythms of drinking activity in the house musk shrew. Experimental Animals, 41, 515-517 (in Japanese).

Aoki, S., Saito, T. R., Ebukuro, S., Hioki, K., \& Takahashi, K. W. 1993 Diurnal rhythms in locomotor activity of the house musk shrew, Suncus murinus. Experimental Animals, 42 , 103-105 (in Japanese).

Ansell, W. F. H. 1964 Captivity behavior and postnatal development of the shrew Crocidura bicolor. Proceedings of the Zoological Society of London, 142, 123-127.

Balakrishnan, M., Nair, G. N. A., \& Alexander, K. 
TSUJI, et al.: The house musk shrew as a new laboratory animal

M. 1972 A study on some aspects of the physiology of the Indian musk shrew, Suncus murinus viridescens (Blyth). Journal of Animal Morphology and Physiology, 21, 98106.

Balakrishnan, M., \& Alexander, K. M. 1979 A study on aspects of feeding and food utilization of the Indian musk shrew, Suncus murinus viridescens (Blyth). Physiology and Behavior, 22, 423-428.

Dippenaar, N. J. 1979 Notes on the early postnatal development and behaviour of the tiny Crocidura bicolor Bocage 1889 (Insectivora : Soricidae). Mammalia, 43, 83-91.

Dryden, G. L. 1968 Growth and development of Suncus murinus in captivity on Guam. Journal of Mammalogy, 49, 51-62.

Dryden, G. L. 1969 Reproduction in Suncus murinus. Journal of Reproduction and Fertilization, Supplement : 6, 377-396.

Fons, R. 1972 La musaraigne musette Crocidura russula (Herman 1780). Science et Nature, 112, 23-28.

Furumura, K., Kuriki, R., Ohta, K., \& Yokoyama, A. 1985 Reproduction in Suncus murinus. In K. Kondo (Ed.), Suncus murinus : Biology of the Laboratory Shrew Japan Science Societies Press: Tokyo (in Japanese). Pp. 126139

Grünwald, A. V., \& Möhres, F. P. 1974 Beobachtungen zur Jugendentwicklung und Karawanenbildung bei Weisszahnspitzmausen (Soricidae-Crocidurinae). Zeitschrift für Saugetierkunde, 39, 321-337.

Hanzak, J. 1966 Zur Jugendentwicklung der Gartenspitzmaus Crocidura suaveolens (Pallas 1821). Lynx, 6, 67-74.

Ishii, K., \& Tsuji, K. 1987 A study on the learning ability of the house musk shrew, Suncus murinus : I. Reversal learning of the position discrimination. Bulletin of the Nagoya University School of Letters, 99, 77-84 (in Japanese).

Ishii, K., \& Tsuji, K. 1988 A study on the learning ability of the house musk shrew, Suncus murinus : II. Effects of domestication on the learning of escape from aversive situation. Bulletin of the Nagoya University School of Letters, 102, 59-64 (in Japanese).

Jerison, H. J. 1973 Evolution of the Brain and Intelligence. Academic Press: New York.

Kawano, K. 1992 Aggressive behavior of the domesticated house musk shrew (Suncus murinus) in intermale, interfemale and heterosexed interactions. Journal of Ethology, 10, 119-131.

Kawano, K., \& Tsuji, K. 1991 Process of behavioural independence between mother and offsprings of the house musk shrew Suncus murinus. Proceedings of the 22nd International Ethological Conference (Kyoto, Japan).

Matsuo, T., \& Tsuji, K. 1987 Diurnal activity rhythms of the domesticated house musk shrew, Suncus murinus. Iden, 41, 45-48 (in Japanese).

Niethammer, G. 1950 Zur Judenpflege und Orientierung der Hausspitzmaus (Crocidura russula Herm). Bonner Zooloisch Beitrage, 1, 117-125.

Oda, S., \& Kondo, K. 1977 Domestication of the wild Insectivora. Experimental Animals, 26, 273-280 (in Japanese).

Rissman, E. F. 1987 Social variables influence female sexual behavior in the musk shrew (Suncus murinus). Journal of Comparative Psychology, 101, 3-6.

Rissman, E. F., \& Bronson, F. H. 1987 Role of the ovary and adrenal gland in the sexual behavior of the musk shrew, Suncus murinus. 
Biology and Reproduction, 36, 664-668.

Schacht, H. 1910 Hausspitzmaus. Zoologisch Garten, A. F., 318.

Tsuji, K. 1987 Sexual behaviour in the domesticated house musk shrew (Suncus murinus). Proceedings of the 20th International Ethological Conference (Madison, USA).

Tsuji, K. 1988 Caravaning in the house musk shrew Suncus murinus: A species-specific behaviour. Iden, 42 (11), 33-38 (in Japanese).

Tsuji, K. 1988 Role of the male's pacifying vocalization in mating of the domesticated house musk shrew Suncus murinus. Proceedings of the Summer Meeting of the Association for the Study of Animal Behaviour (Sussex, UK).

Tsuji, K. 1989 Male's aggression to the partner female after ejaculation in the house musk shrew Suncus murinus. Proceedings of the 21st International Ethological Conference (Utrecht, The Netherlands).

Tsuji, K. 1990 Sexual behaviour and male's postejaculatory attack to the female in the domesticated house musk shrew Suncus murinus. Proceedings of the 12th Ethologentreffen (Vienna, Austria).

Tsuji, K. 1991 Correlative analysis of the early and sexual behaviours in the domesticated house musk shrew Suncus murinus. Proceedings of the 22nd International Ethological Conference (Kyoto, Japan).

Tsuji, K. 1993 Postejaculatory attack of the male house musk shrew Suncus murinus. Proceedings of the 23rd International Ethological Conference (Torremolinos, Spain).

Tsuji, K., \& Ishikawa, T. 1982 Life mode and behaviour of the house musk shrew Suncus murinus var. riukiuanus. Japanese Journal of Mammalogy, 9, 96-103 (in Japanese).
Tsuji, K., \& Ishikawa, T. 1984 Some observations of the caravaning behaviour in the house musk shrew Suncus murinus. Behaviour, 90, 167-183.

Tsuji, K., Matsuo, T., \& Ishikawa, T. 1986 Developmental changes in the caravaning behaviour of the house musk shrew Suncus murinus. Behaviour, 99, 117-138.

Tsuji, K., \& Naruse, I. 1985 Behavior characteristics in the domesticated house musk shrew, Suncus murinus. In Kondo, K (Ed.), Suncus murinus : Biology of the Laboratory Shrew. Japan Science Societies Press: Tokyo (in Japanese). Pp 459-475.

Vlasak, P. 1972 The biology of reproduction and postnatal development of Crocidura suaveolens Pallas 1811 under laboratory conditions. Acta Universitat Carolinae, Biologica, 207-292.

Vogel, P. 1970 Biologische Beobachtungen an Etruskerspizmausen (Suncus etruscus Savi. 1932). Zeitschrift für Säugetierkunde, 35, 173- 185.

Wahlström, A. 1929 Beiträge zur Biologie von Crocidura leucodon (Herm.). Zeitschrift für Säugetierkunde, 4, 157-185.

Wahlström, A. 1930 Eine Spitzmauskarawane. Kosmos, Stuttgart, 27, 256.

Watanabe, I., Ohkouchi, T., \& Toyama, K. 1980 Electrophysiological and histological study on retina of the house musk shrew Suncus murinus. Jounal of the Ophthalmological Society of Japan, 84, 15-17 (in Japanese).

Zippelius, H.-M. 1957 Zur Karawanenbildung bei der Feldspitzmaus. Bonner Zoologisch Beitrage, 8, 81-85.

Zippelius, H.-M. 1972 Die Karawanenbildung bei Feld- und Hausspitzmaus. Zeitschrift für Tierpsychologie, 30, 305-320.

(Received Oct. 27, 1998 ; accepted May 6, 1999) 